\title{
The role of personality traits in pain perception and disability.
}

Citation for published version (APA):

Peters, M. L., \& Vancleef, L. M. G. (2008). The role of personality traits in pain perception and disability. Reviews in Analgesia, 10, 11-21. https://doi.org/10.3727/154296108783994022

Document status and date:

Published: 01/01/2008

DOI:

10.3727/154296108783994022

Document Version:

Publisher's PDF, also known as Version of record

Document license:

Taverne

Please check the document version of this publication:

- A submitted manuscript is the version of the article upon submission and before peer-review. There can be important differences between the submitted version and the official published version of record.

People interested in the research are advised to contact the author for the final version of the publication, or visit the DOI to the publisher's website.

- The final author version and the galley proof are versions of the publication after peer review.

- The final published version features the final layout of the paper including the volume, issue and page numbers.

Link to publication

\footnotetext{
General rights rights.

- You may freely distribute the URL identifying the publication in the public portal. please follow below link for the End User Agreement:

www.umlib.nl/taverne-license

Take down policy

If you believe that this document breaches copyright please contact us at:

repository@maastrichtuniversity.nl

providing details and we will investigate your claim.
}

Copyright and moral rights for the publications made accessible in the public portal are retained by the authors and/or other copyright owners and it is a condition of accessing publications that users recognise and abide by the legal requirements associated with these

- Users may download and print one copy of any publication from the public portal for the purpose of private study or research.

- You may not further distribute the material or use it for any profit-making activity or commercial gain

If the publication is distributed under the terms of Article $25 \mathrm{fa}$ of the Dutch Copyright Act, indicated by the "Taverne" license above, 


\title{
The Role of Personality Traits in Pain Perception and Disability
}

\author{
Madelon L. Peters and Linda M. G. Vancleef \\ Department of Medical Clinical and Experimental Psychology, Maastricht University, 6200 MD Maastricht, The Netherlands
}

According to the biopsychosocial model of chronic pain and disability, the experience of pain is the result of a dynamic interaction between physiological, psychological, and social factors. Fear-avoidance beliefs have been identified as being among the most prominent psychological factors influencing the development and persistence of chronic pain. This article reviews the evidence that personality traits contribute to the process of pain chronification by making people more vulnerable to respond to physical threat in an anxious and avoidant manner. We will consider three potential vulnerability factors: negative affectivity, anxiety sensitivity, and injury/illness sensitivity. For all three factors evidence has been found that they may indeed contribute to maladaptive ways of dealing with pain. Recently researchers have also begun to consider the role of resilience factors that may protect people against maladaptive cognitive and behavioral reactions to acute and chronic pain. We will review the evidence for three of these potential resilience factors: optimism, hope, and (generalized) self-efficacy. It is concluded that there is at least some evidence pointing towards a role of these three factors in chronic pain and disability, but the evidence for trait characteristics acting as resilience factors in chronic pain is less compelling than that for traits acting as vulnerability factors.

Key words: Vulnerability factors; Resilience factors; Personality traits; Chronic pain; Disability

\section{Introduction}

The biopsychosocial model is now widely accepted as the most heuristic perspective to the understanding and treatment of chronic pain disorders (25). The basic tenet of the biopsychosocial model is that pain is the result of a dynamic interaction between physiological, psychological, and social factors that determine outcome in terms of illness, disability, and suffering. Each individual experiences pain uniquely, because psychological and social factors interact with physical pathology to modulate a patient's reaction to symptoms.

However, the biopsychosocial model is a very general framework. The psychological component of the model encompasses many different factors and processes that may determine how an individual experiences pain, whether or not acute pain will persist, and whether the individual in pain will respond to treatment. During the past decades, several more specific models of chronic pain have been developed, which emphasize the role of a few supposedly crucial elements in the process of pain amplification and persistence. One of these models is the fear-avoidance model of chronic musculoskeletal pain (80), which has received increasing empirical support, mainly in the area of chronic low back pain $(17,24,42)$, but also in other musculoskeletal pain complaints and nonmusculoskeletal pain $(28,41,48)$. The starting point of this review will be the fear-avoidance model of chronic pain. First, the model and its basic tenets will be described. Next, the link with personality traits will be explored. The original fear-avoidance model does not include personality traits, but it will be proposed that certain traits make people more vulnerable to respond to physical threat in an anxious and avoidant manner, increasing the likelihood that they will enter the vicious circle of increased pain and disability as proposed by the fearavoidance model. The main vulnerability factors to be

Address correspondence to Madelon L. Peters, Department of Medical Clinical and Experimental Psychology, Maastricht University, P.O. Box 616, 6200 MD Maastricht, The Netherlands. Tel: 3143 3881603; Fax: 3143 3884155; E-mail: Madelon.Peters@dep.unimaas.nl 
discussed are negative affectivity, anxiety sensitivity, and injury/illness sensitivity (see Table 1 for brief description of these and other terms). First, the relationship among these constructs, and between these constructs and other affective concepts, will be briefly discussed. Next, empirical evidence for their proposed role as vulnerability factors in chronic pain will be presented. The last part of the review will focus on resilience factors for chronic pain. What personality traits may protect against entering the fear-avoidance pain cycle when an individual is confronted with an acute pain situation? And which traits protect against high levels of disability and distress in people who have a chronic pain condition? The trait factors hope, optimism, and self-efficacy will be reviewed.

\section{Fear-Avoidance Models of Chronic Pain}

In 1983 Lethem et al. introduced the "fear-avoidance model of exaggerated pain perception" to explain the desynchrony between the sensory component of pain and pain behavior (39). Since then, the interest in the role of fear and avoidance behavior in the development and exacerbation of chronic pain has increased enormously, and this has given rise to the development of contemporary fear-avoidance models with their increased emphasis on cognitive processes $(7,52,80)$.
The tenets of contemporary fear-avoidance models can be summarized as follows. When pain is perceived following injury, an individual's idiosyncratic beliefs, expectations, and learning history will determine the extent to which pain is catastrophically interpreted. Most people will consider pain as an unpleasant experience, yet not particularly threatening or indicative of an impending catastrophe. After a while they will resume their normal activities and recovery from the acute pain episode is likely to occur. However, some individuals react to pain in an exaggerated negative manner. A catastrophic interpretation of pain gives rise to painrelated fear (i.e., fear of pain, fear of injury, or fear of movement) and subsequently avoidance of potentially painful activities. This may lead to a self-perpetuating negative spiral with avoidance of more and more (daily) activities, leading to functional disability and possibly also to social isolation and depression. In turn, physical deconditioning and depression may fuel the fear-avoidance cycle by increasing pain intensity and increasing the fearful appraisal of and attention to pain (7).

Since the formulation of the fear-avoidance models of pain there has been an explosion of research on the role of catastrophizing and pain-related fear in the etiology and persistence of chronic pain [for reviews see $(31,71,80)]$. The evidence that catastrophizing and pain-

Table 1. Glossary of terms

\begin{tabular}{|c|c|}
\hline Term & Description \\
\hline Anxiety sensitivity & Fear of anxiety-related sensations. One of the three fundamental fears. \\
\hline ASI & Anxiety Sensitivity Index: 16-item questionnaire to measure fear of anxiety-related sensations. \\
\hline Dispositional optimism & Stable personality trait reflecting generalized positive expectations about the future. \\
\hline EAST & $\begin{array}{l}\text { Extrinsic Affective Simon Task: Experimental paradigm to measure automatically activated emotional } \\
\text { evaluation of stimuli. }\end{array}$ \\
\hline Fundamental fear & $\begin{array}{l}\text { Fear of inherently noxious stimuli. Three fundamental fears are identified: anxiety sensitivity, injury/illness } \\
\text { sensitivity, and fear of negative evaluation. }\end{array}$ \\
\hline Hope & $\begin{array}{l}\text { State or trait characteristic reflecting the believe in one's capacity to generate pathways to a desired goal } \\
\text { as well as the perceived capacity to use these pathways. }\end{array}$ \\
\hline Injury/illness sensitivity & $\begin{array}{l}\text { Fear of having an illness or injury or becoming ill or injured in the future. One of the three fundamental } \\
\text { fears. }\end{array}$ \\
\hline ISI & Injury/illness Sensitivity Index: 11 -item questionnaire to measure fear of injury/illness. \\
\hline Negative affectivity & General and stable personality trait to experience a broad range of negative feelings. \\
\hline Pain catastrophizing & Exaggerated negative interpretation of the meaning of pain. \\
\hline Resilience & $\begin{array}{l}\text { Process of adapting well in the face of adversity, trauma, tragedy, threats, or stress; "bouncing back" from } \\
\text { difficult experiences. }\end{array}$ \\
\hline Self-efficacy & People's beliefs about their capabilities to produce effects or attain behavioral goals. \\
\hline
\end{tabular}


related fear are associated with increased disability and impaired physical performance in chronic pain is overwhelming. A systematic review of the literature on psychological risk factors in back and neck pain indicated that the evidence for the association between fear-avoidance beliefs and increased pain and disability was of the highest level [level A evidence, meaning that the association is supported by at least two good quality prospective studies (41)]. In addition, prospective studies demonstrated that fear-avoidance beliefs in patients seeking care for acute pain may be predictive of pain persistence, disability, and long-term sick leave $(14,17,24,38)$. Catastrophizing and pain-related fear are also related to the future inception of (back) pain in the general population $(42,53,62)$.

\section{Personality Traits and Vulnerability for Entering the Negative Fear-Avoidance Pain Spiral}

According to the fear-avoidance models of chronic pain, the majority of people experiencing an acute pain episode do not make a catastrophic interpretation about the meaning of pain. However, a significant minority of individuals do react with catastrophizing and fear to pain, and an important question is what factors predispose some individuals to make catastrophic misinterpretations of pain sensations. Pain cognitions are largely shaped by an individual's learning history, either through direct experience, modeling, or information from others. These learning experiences may interact with trait characteristics and the global outlook on the world that an individual holds. That is, temperamental or personality factors may predispose some people to attach a more negative meaning to potentially threatening situations in general and to be more susceptible to maladaptive beliefs. Temperament is supposed to be (at least partly) heritable and to show continuity throughout life; personality in adulthood reflects the molding of underlying temperament by life experiences. Temperament and personality may act as vulnerability factors that predispose towards catastrophic misinterpretation of pain sensations and maladaptive pain beliefs.

Personality traits that have been considered as vulnerability factors include negative affectivity, anxiety sensitivity, and, more recently, injury/illness sensitivity $(25,32)$. Both anxiety sensitivity and injury/illness sensitivity are considered to be fundamental fears (or sensitivities) together with fear of negative evaluation $(55,72)$. A fear is defined as fundamental when it satis- fies two criteria: 1) it is a fear of inherently noxious stimuli, and 2) common fears can be logically deduced from them (55).

The relationship between negative affectivity and the fundamental fears may be conceptualized according to the hierarchical model of negative emotions as proposed by Lilienfeld et al. (40). According to this hierarchical model, negative affectivity - a stable but very general emotional vulnerability factor-resides in the top of the hierarchy. On the next level of the model, the negative emotions are differentiated according to the type of affect: trait anxiety, trait anger, and trait alienation. Trait anxiety is further differentiated in the three fundamental fears of anxiety sensitivity, injury/illness sensitivity, and fear of negative evaluation. Common fears and phobias (e.g., social phobia, blood phobia) can be found at the bottom of the negative emotions pyramid, with each common fear or phobia resulting from one specific fundamental fear. For instance, social phobia results from the higher order factor fear of negative evaluation and blood phobia from injury/illness sensitivity (72). Fear of pain and fear of movement can also be considered as common fears and are supposed to result from injury/illness sensitivity $(32,78)$. In the following subsections we will first consider the evidence for the most global trait according to the hierarchical model (i.e., negative affectivity), as a vulnerability factor in the etiology and persistence of chronic pain. This will be followed by a discussion of the two most relevant fundamental fears in the context of pain: anxiety sensitivity and injury/illness sensitivity.

\section{Negative Affectivity}

Negative affectivity is considered to be a heritable and stable tendency to experience a broad range of negative emotions and to view the world as threatening and distressing (83). Negative affectivity is related to a variety of psychological disorders, most notably anxiety disorders and depression. Moreover, early research has demonstrated that people high in negative affectivity are more vigilant for all kinds of (harmless) physical sensations (84). It is therefore not surprising that negative affectivity has been proposed as a predisposing factor in the emergence of pain-related fear and thus for entering the vicious fear-avoidance pain cycle (80).

Heightened levels of general negative affect are indeed quite common in patients with chronic pain; however, it is unclear whether this was present before 
chronic pain started, and thereby qualifies as a vulnerability factor, or whether this is the result of the painful condition (32). To establish the prognostic role of trait negative affectivity in the development of chronic pain, the presence of this trait should be established prior to the occurrence of the painful condition. This would require large population-based studies, which so far for negative affectivity have not been performed. An approximation of such a design is the measurement of a trait in the early phase of a pain episode and then measure (non)recovery. Radanov et al. (54) have used such a design in people who had sustained whiplash trauma after a motor vehicle accident, but found no evidence that negative affectivity was associated with an increased risk of chronic neck pain and disability.

Another method to explore whether negative affectivity can be considered as a vulnerability factor for chronic pain is to study sensitivity to experimentally induced pain in healthy volunteers. Indeed, people with a high level of negative affectivity have a lower pain tolerance (22) and experimental induction of negative affect reduced tolerance for cold pressor pain (86). Moreover, negative affectivity has also been found to be associated with the tendency to interpret ambiguous bodily sensations in a negative manner $(68,69)$. These experimental studies suggest that because high negative affective individuals are more sensitive to pain and attach a negative meaning to pain and other bodily signals, acute pain episode may elicit stronger fear responses in them. This may subsequently place them at risk to enter the negative fear-avoidance pain cycle.

\section{Anxiety Sensitivity}

Anxiety sensitivity is defined as the fear of anxietyrelated sensations and is conceived as a personality trait that is partly heritable $(55,70)$. Individuals with high anxiety sensitivity interpret unpleasant physical sensations (e.g., sweating, rapid heart beating, feeling faint) more often as a sign of danger than individuals with low anxiety sensitivity. Elevated levels of anxiety sensitivity have been found in several emotional disorders, but have most consistently been related to panic disorder (73). There is growing evidence that suggests that anxiety sensitivity is also a risk factor for the development and persistence of chronic pain and disability (9). Studies in patients with various acute and chronic pain disorders demonstrated that high levels of anxiety sensitivity are associated with more distress, increased analgesic use, and poorer physical and social functioning [for reviews see $(8,9,32)]$. Structural equa- tion and mediational models furthermore suggest that anxiety sensitivity may indeed be a predisposing factor that exacerbates fear-avoidance beliefs and the negative interpretation of bodily sensations, which in turn leads to increased pain sensitivity and avoidance $(8,36)$.

To determine whether anxiety sensitivity is really a vulnerability factor and not merely a correlate of the chronic pain experience (cf. supra) studies in nonclinical samples using experimental pain induction have been performed. As predicted, individuals with a high level of anxiety sensitivity had a lower pain threshold and reported more pain during the cold pressor test $(33,34,37,61)$. Moreover, individuals with high anxiety sensitivity demonstrated both an attentional as well as an interpretational bias for physical threat cues $(6,34$, $35)$. Interestingly, the negative interpretational bias for bodily sensations mediated the effect of anxiety sensitivity on the affective pain response during induction of cold pressor pain $(34,36)$. These findings suggest that anxiety sensitivity may indeed be a predisposing factor that causes people to react to an acute pain experience with maladaptive cognitions and that increases the chance to react with fear-avoidance to pain.

\section{Injury/Illness Sensitivity}

Recently we have proposed that injury/illness sensitivity may be another vulnerability factor for chronic pain. We hypothesized that injury/illness sensitivity is the fundamental fear that is most strongly associated with common pain-related fears, and that it may be a more specific vulnerability factor for chronic pain and disability than anxiety sensitivity (78). The items of the inventories that are used to measure anxiety sensitivity and injury/illness sensitivity - the ASI and ISI, respectively (72) -illustrate that injury/illness sensitivity is conceptually stronger related to the content of fear-avoidance beliefs of chronic pain patients than anxiety sensitivity. The ASI contains items that apply very specifically to panic symptoms (e.g., fear of heart beating fast), while the ISI contains items that reflect worries about one's future physical condition (e.g., worrying about getting injured). In addition, in his analysis of the relationship between fundamental fears and common fears, Taylor (72) showed that anxiety sensitivity was most predictive of agoraphobia, while injury/illness sensitivity was most predictive of blood injury fears. Because in this study pain-related fear constructs were not included, we have recently conducted a similar study in which the relationship between the three fundamental fears and fear of pain and 
pain catastrophizing was examined (78). The three fundamental fears-injury/illness sensitivity, anxiety sensitivity, fear of negative evaluation - and the higher order factor trait anxiety were tested for their independent contribution to pain catastrophizing and fearavoidance beliefs. Injury/illness sensitivity appeared to be the single best predictor of pain catastrophizing, fear of pain, and pain avoidance. In a second experiment, we tested the predictive validity of the three fundamental fears and trait anxiety for actual fear of pain (78). We subjected healthy volunteers to three different pain induction procedures (ischemic pain, electrical pain, and heat pain) and before each test, participants scored how much they feared the pain they would experience during the procedure. The single best predictor of actual fear of pain was injury/illness sensitivity, whereas neither anxiety sensitivity nor trait anxiety significantly contributed to the explained variance in anticipatory fear.

A subsequent study tested the differential predictive value of the three fundamental fears for interpretation biases for panic-related symptoms, pain-related symptoms, and social situations (76). As expected, the negative interpretation of panic-related symptoms was uniquely predicted by anxiety sensitivity, of social situations by fear of negative evaluation, while both anxiety sensitivity and injury/illness sensitivity predicted the negative interpretation of pain-related symptoms. In another study, we found that both anxiety sensitivity and injury/illness sensitivity were related to a stronger automatic threat appraisal of words that reflected health threats, as measured with the EAST reaction time paradigm (77). The association was somewhat stronger for injury/illness sensitivity and, in fact, the association for anxiety sensitivity was only marginally significant. Nevertheless, the results of the two studies taken together do suggest that both anxiety sensitivity and injury/illness sensitivity may shape the cognitive and affective response to pain and other bodily sensations and thereby constitute vulnerability factors for developing and maintaining chronic pain. However, it may be speculated that both fundamental fears may predispose towards a different and specific maladaptive reaction pattern when confronted with pain. We also examined the relationship of the two relevant fundamental fears with self-reported use of health care services (visits to general practitioner, physiotherapist, medication use) in the past year and with the selfreported tendency to engage in health-protecting behavior. For the latter we used vignettes describing situ- ations that could potentially signal damage to the body (e.g., having pain in the wrist after a fall; occasional pain in the knee) and the likelihood of performing safety behaviors was assessed (e.g., going to the GP, wearing a brace). Interestingly, injury/illness sensitivity was the single best predictor of safety behavior regarding physical health (prevention and protection), while anxiety sensitivity was the single best predictor of actual use of health care services during the last year (77). This has led us to speculate that injury/illness sensitivity may especially predispose towards anxiety and avoidance of potential future harm whereas anxiety sensitivity may predispose towards more negative responses once the pain problem has been established (77).

\section{Personality Traits Acting as Resilience Factors in Chronic Pain}

Relative to the attention that has been devoted to negative predisposing factors for chronic pain and disability, resilience factors promoting adjustment to acute and chronic pain have received only little attention. Personality traits that act as resilience factors may protect against maladaptive cognitions about pain (e.g., catastrophizing) and against the instigation of fearavoidance beliefs in pain-related situations. Moreover, in people who have a chronic pain condition, certain personality traits may stimulate more adaptive coping with and better adjustment to pain, which protects against increased levels of disability and distress. We will discuss three potential resilience factors for (adjustment to) chronic pain: optimism, hope, and selfefficacy. Other potential resilience factors that have been brought in relation with better adjustment to pain are acceptance (47) and benefit finding (1), but these are not personality traits and therefore will not be discussed here.

The concepts of hope, optimism, and self-efficacy are closely related to each other, yet reflect subtle differences in the underlying theoretical models (65). Both (dispositional) optimism and (trait) hope are considered relative stable personality characteristics that reflect generalized positive expectations about the future (66). The difference between the two concepts is the emphasis on the origins of this positive outcome expectancy. According to the most prominent theoretical conceptualization of optimism (18), it is irrelevant where the favorable expectancies are derived from (e.g., personal ability, help from others, fate, etc.). It is the positive outcome expectancy itself that matters 
(57). In contrast, the Hope theory of Snyder (65) emphasizes the role of the individual in bringing about the desired outcome. Hope is defined as a cognitive mindset in which people believe that they can produce routes to desired goals, along with the motivation to use those routes. Two different types of expectancies are distinguished: pathway thoughts and agency thoughts. Pathway thoughts signify the perceived capacity to generate routes to a desired goal (e.g., "I can think of many ways to get the things in life I want"). Agency thoughts signify the perceived capacity to use these pathways to reach this desired goal (e.g., "I meet the goals that I set for myself').

Hope-and especially the agency component-is also closely related to self-efficacy. Like hope, selfefficacy refers to an individual's beliefs concerning his/her ability to attain behavioral goals (11). According to Bandura (11), self-efficacy is domain specific (i.e., it is possible to have different levels of self-efficacy in different domains of functioning or in different situations). However, others have proposed generalized self-efficacy as a trait-like concept that refers to a global confidence in one's coping ability across a wide range of situations $(45,63)$. The role of optimism, hope, and (generalized) self-efficacy as potential resilience factors in chronic pain will be discussed below.

\section{Optimism}

Review of the literature suggests that optimism may be one of the most important personality traits in relation to adjustment to chronic illnesses. Optimism protects against depression and is related to less distress in people with various kinds of diseases (e.g., bone marrow transplantation, cancer, AIDS) [for reviews see $(18,58)]$. Moreover, prospective studies demonstrated that optimism is associated with faster recovery after surgical procedures $(58,60)$ and greater subjective well-being after surgery, which may still be apparent several years after the operation took place $(23,60)$.

Only few studies have examined dispositional optimism specifically in relation to adaptation to chronic pain. Treharne et al. (75) demonstrated that optimism is associated with less depression, higher life satisfaction, and less pain in patients with rheumatoid arthritis, in the early and intermediate stages of disease. Tennen et al. (74) examined the relationship of dispositional optimism with daily symptoms, mood, and functioning rheumatoid arthritis patients. High optimistic patients reported finding more benefit from their illness, they experienced significantly better daily mood, and had fewer days with pain-related activity limitations. In another daily diary study with woman suffering from fibromyalgia, it was shown that woman higher on optimism were less likely to consider their pain and fatigue as obstacles to achieving health goals (3).

It has also been demonstrated that pessimism and optimism may be differentially related to adaptation to chronic pain (2). In patients with rheumatoid arthritis high levels of pessimism were related to more negative daily mood, poorer sleep, and more activity limitations, whereas optimism was related to more positive daily mood only. In addition, optimism was associated with higher perceived social support, higher perceived pain control, more benefit finding, and more use of coping strategies. Pessimism was associated with more pain catastrophizing, more depression, and less perceived coping efficiency. The separate contribution of optimism and pessimism found in this study converges with those from another study (16). Separate measures of dispositional optimism and dispositional pessimism were obtained from a large group of older individuals with knee pain. Especially for the pessimism scale significant associations with objectively assessed physical performance were found (i.e., walking, lifting, climbing stairs, getting in a car). High pessimistic individuals performed worse on all task, while high optimism was related to better performance on the walking task only (16).

An important mechanism underlying the effects of optimism and pessimism on adaptation to chronic pain may be differences in coping behavior (10). In general, pessimists use avoidant coping strategies and denial more often, and optimists employ more problem-focused coping strategies. When problem-focused coping is not possible, optimists turn to coping strategies such as acceptance, use of humor, and positive reframing of the situation $(10,59)$. Indeed, Novy et al. (49) found that chronic pain patients high in dispositional optimism in combination with a high level of perceived control of pain, more often used the coping strategies diverting attention, coping self-statements, and increasing activity level, and less often catastrophized their pain. High dispositional optimism combined with low levels of perceived control was associated with increased use of the coping strategies reinterpreting pain and praying and hoping, and again with less catastrophizing. Thus, it may not be the use of any specific coping strategies that protects against disability and distress, but the flexibility of coping (18).

In sum, there is convincing evidence for the role of 
optimism in coping with and adaptation to chronic pain. But what about resilience for developing chronic pain? It may be speculated that optimistic individuals who experience an acute pain episode are less prone to become trapped in the negative fear-avoidance pain cycle because they catastrophize less about the consequences of pain and use less avoidant coping. No longitudinal prospective studies on persistence of acute pain in relation to optimism and pessimism have been carried out yet. Indirect evidence that pessimism may be related to activity avoidance during an acute pain episode was obtained in a study on resumption of normal activity after inguinal hernia operations (15). Postsurgery patients with a high level of pessimism were significantly slower to take up routine everyday activities than patients with low levels of pessimism. Optimism was not predictive of outcome in this study.

Recently we have begun to consider the influence of optimism on pain-related cognitive biases. In healthy pain-free individuals, optimism protected against negative interpretations of ambiguous situations across various domains (panic related, social, general) including pain-related situations (76). Participants in this study had to indicate which explanation they found the most plausible solution of an ambiguous situation. Optimists less often chose the catastrophizing explanation. In another study, we examined the role of optimism in relation to responses to experimentally induced pain. In the prospect of experiencing painful electrical stimulation, high optimistic individuals indicated less anticipatory fear for this stimulus and they expected the electrical stimulus to be less painful. Moreover, high optimistic individuals reported to have experienced less fear during stimulation (79).

Finally, we have examined the role of optimism as a potential resilience factor for the development of chronic postsurgical pain and disability in a large-scale prospective study with patients undergoing various types of surgical interventions (51). Patients undergoing elective surgery $(N=1490)$ filled in questionnaires on potential vulnerability and resilience factors preoperatively. Trait anxiety, surgical anxiety, and pain catastrophizing were considered as vulnerabilities, and optimism and generalized self-efficacy as resilience factors. After the operation patients were followed for 4 days to record acute postoperative pain and shorttime functional recovery. Six months later patients were approached to rate their present pain and functioning, perceived global recovery, and quality of life. Logistic regression analyses were used to predict the level of acute postoperative pain and poor perceived recovery on day 4 (67). All analyses were controlled for demographic variables (age, sex, and education), preoperative pain, type of operation (minor, intermediate, major), body region involved, and type of anesthesia used. Optimism did not predict pain intensity during the 4 days after surgery. However, poor functional recovery on day 4 was significantly related to optimism as assessed before the operation (odds ratio: 0.70) after controlling for somatic and other psychological predictors. The follow-up data showed that optimism was still related to functional outcome 6 months later (51). Optimists reported higher levels of perceived global recovery and higher quality of life at 6 months postoperation. Chronic postsurgical pain was predicted by various somatic factors and preoperative surgical fear, but not by optimism. Thus, it appears that optimism is especially related to (short- and long-term) functional and emotional recovery from surgical intervention.

\section{Hope}

The role of hope in physical well-being and pain has mainly been put forward by Snyder et al. (65). Snyder proposed that when people with high hope are confronted with physical illness, they more often focus on what they can do to recuperate compared to low-hope individuals. When the condition is nonrepairable, and an individual's original goals are blocked, people with high hope show flexibility in finding alternative life goals. On the other hand, people with low hope show a tendency to catastrophize their condition and they show stronger self-focus and self-pity, which may increase anxiety and compromise the healing process (65). In the case of pain, high hope could facilitate focusing attention away from pain; that is, the focus is on the desired goals instead of the nondesired stimuli (pain) related to the goals' pursuit (64).

Only few studies have empirically examined whether hope affects the reaction to acute pain stimuli or influences adaptation to chronic pain. Using the cold pressor test to induce experimental pain in healthy volunteers, Snyder and colleagues found that individuals with high hope tolerated the pain stimulus longer than those with low hope (64). A second experiment did not confirm the association with pain tolerance but found a significant association between hope, pain threshold, and pain intensity reports. Moreover, this association appeared to be specific for hope. Other personality traits that were included, among which optimism and 
self-efficacy, did not show a significant relationship with either pain threshold or pain intensity.

Affleck and Tennen (1) found that fibromyalgia patients with high-hope levels reported to find more benefit from their disease than patients with lower levels of hope, even after controlling for the related constructs of optimism and pessimism. Moreover, a daily diary study demonstrated that high-hope individuals also used more benefit reminding as a daily coping strategy with pain, and benefit reminding was associated with better mood. Thus, hope may lead to a more positive appraisal of one's painful condition and protect against distress and depression.

\section{Self-Efficacy}

Self-efficacy is the conviction that one can successfully perform a certain task or produce a desirable outcome (11). When encountering a health threat high self-efficacious people may be more motivated to engage in health promoting behaviors and adhere better to treatment recommendations because they have higher performance success expectancies. Also, they are less likely to give up an activity when facing barriers. Most research in the domain of adaptation to health threats has focused on domain-specific self-efficacy, but more recently interest in a more trait-like generalized self-efficacy has grown $(19,45,46,63)$. Generalized self-efficacy reflects the individual's perception of his/her ability of meeting task demands across a variety of different situations (19). Generalized self-efficacy is associated with better quality of life and emotional adjustment across different diseases [e.g., epilepsy, (27); cystic fibrosis (81); cancer (13)].

So far, most studies on the role of self-efficacy in pain patients have focused on domain-specific selfefficacy. Self-efficacy scales for dealing with pain have been developed that measure how patients evaluate their ability to function despite pain $(4,5)$. This very specific form of self-efficacy has been found to be positively associated with actual physical and psychological functioning in chronic pain patients $(5,85)$. There has been one study that examined the role of generalized self-efficacy in relation to adaptation to arthritis pain. In patients with rheumatoid arthritis, generalized self-efficacy proved to be related to greater psychological well-being, both cross-sectionally and longitudinally (12).

High self-efficacy may not only lead to better adjustment in chronic pain patients, it may also protect against an exaggerated negative affective reaction to acute pain. For instance, Lowe (44) demonstrated that high generalized self-efficacy was associated with less childbirth fears (e.g., losing control during delivery, fear of the painful contractions). However, again most studies in this area have focused on domain-specific self-efficacy. Laboratory studies demonstrated that such domain-specific self-efficacy is associated with less fear and avoidance of experimentally induced pain $(21,26,30,56)$. To investigate the causal role of selfefficacy in higher pain tolerance, Litt manipulated the level of self-efficacy beliefs regarding the ability to exert control over pain in healthy individuals (43). Participants in the high self-efficacy condition were shown to have higher tolerance for cold pressor pain compared to those in the low self-efficacy condition.

Recently, we have conducted a similar experiment in healthy volunteers in which we manipulated the amount of perceived control over an electrical pain stimulus and the level of self-efficacy in exerting this control (79). Participants in the high self-efficacy condition were led to believe that they had a more than average ability to apply a (bogus) technique to control their pain, while the participants in the low self-efficacy condition were led to believe that they had inferior ability to use this technique. We also included a measure of generalized self-efficacy, which was administered prior to the experimental procedure. Results showed that participants in the high self-efficacy condition had less fear of the electrical pain stimulus and also experienced less pain in comparison with participants in the low self-efficacy condition. In addition, generalized self-efficacy beliefs also played a role in that these beliefs were associated with less fear of the electrical stimulus independent of the manipulation.

Finally, prospective studies examined the role of self-efficacy in recovery from surgery. Again, these studies have mainly considered domain-specific selfefficacy as a predictor of outcome. Confidence in one's ability to carry out specific performances and to engage in rehabilitation efforts after surgery prior to the start of rehabilitation and larger increases in this confidence over the course of rehabilitation were associated with faster recovery and better long-term outcome (20, 50,82). An intervention to enhance preoperative domain-specific self-efficacy in hysterectomy patients decreased postoperative pain with activity and promoted earlier mobilization (29). In a first attempt to examine whether these findings extend to generalized 
self-efficacy, we included this personality trait as predictor in our study on postoperative pain described above (51). However, preoperatively assessed generalized self-efficacy was not associated with any of the short- or long-term outcomes in this study.

In conclusion, the evidence for domain-specific selfefficacy beliefs in dealing with acute and chronic pain is more compelling than the evidence for the role of generalized self-efficacy. Nevertheless, there are some findings that indicate that self-efficacy as a trait characteristic may also shape the affective and behavioral response to pain. More research on this issue is warranted.

\section{Summary and Conclusion}

This article has reviewed the evidence that personality characteristics play a role in the etiology and persistence of, and adjustment to, chronic pain. Most studies have focused on vulnerability factors for chronic pain and disability, although recently the focus has also shifted to resilience factors that may protect people against maladaptive cognitive and behavioral reactions to acute and chronic pain. With regard to personality traits that may act as vulnerability factor, we have reviewed the evidence for the role of negative affectivity, anxiety sensitivity, and injury/illness sensitivity. Although for all three traits evidence has been found in cross-sectional, experimental, and prospective studies, we propose that anxiety sensitivity and injury/illness sensitivity are more specific and proximal risk factors than negative affectivity, which may be more distally related to maladaptive cognitive and behavioral reactions to pain. Moreover, anxiety sensitivity and injury/ illness sensitivity may both be related to pain behavior and cognitions in a somewhat distinct manner. While injury/illness sensitivity may especially be related to an anxious and avoidant response to situations that may lead to future harm, anxiety sensitivity may be more associated with the negative reaction to a current pain episode.

The evidence for trait characteristics that may act as resilience factors in chronic pain is less compelling. Research has just begun to explore this issue. Most evidence has been found for the role of optimism, both in experimental and prospective studies. Optimism may protect against maladaptive cognitive responses to pain and stimulate active coping with and behavioral confrontation of pain. Hope is another construct that seems promising in this respect, but only little research has been conducted so far. The final trait we have considered is generalized self-efficacy. Although several studies have documented the beneficial effect of domain-specific self-efficacy in dealing with pain, the role of self-efficacy as a more global trait-like construct in relation to pain has been underexposed. More research is clearly needed to examine whether indeed self-efficacy as a stable trait is a valuable concept in relation to adaptation to pain.

All in all there is good evidence that certain personality factors play a role in the etiology and persistence of chronic pain and disability. We propose that these trait characteristics may predispose or protect people to react with maladaptive cognitive, affective, and behavioral responses to acute pain and to situations that are potentially harmful. In this way individuals may have an increased or a decreased risk to enter the maladaptive and self-perpetuating fear-avoidance pain cycle.

\section{References}

1. Affleck, G.; Tennen, H. Construing benefits from adversity: Adaptational significance and dispositional underpinnings. J. Personal. 64:899-922; 1996.

2. Affleck, G.; Tennen, H.; Apter, A. Optimism, pessimism,and daily life with chronic illness. In: Chang, E. C., ed. Optimism \& pessimism. Washington, DC: American Psychological Association; 2001:147-168.

3. Affleck, G.; Tennen, H.; Zautra, A.; Urrows, S.; Abeles, M.; Karoly, P. Women's pursuit of personal goals in daily life with fibromyalgia: A value-expectancy analysis. J. Consult. Clin. Psychol. 69:587-596; 2001.

4. Anderson, K. O.; Dowds, B. N.; Pelletz, R. E.; Edwards, W. T.; Peeters Asdourian, C. Development and initial validation of a scale to measure self-efficacy beliefs in patients with chronic pain. Pain 63:77-84; 1995.

5. Asghari, A.; Nicholas, M. K. Pain self-efficacy beliefs and pain behaviour. A prospective study. Pain 94:85$100 ; 2001$.

6. Asmundson, G. J.; Carleton, R. N.; Ekong, J. Dot-probe evaluation of selective attentional processing of pain cues in patients with chronic headaches. Pain 114:250256; 2005.

7. Asmundson, G. J.; Norton, P. J.; Vlaeyen, J. W. S. Fearavoidance models of chronic pain: An overview. In: Asmundson, G. J.; Vlaeyen, J. W. S.; Crombez, G., eds., Understanding and treating fear of pain. Oxford: University Press; 2004:3-24.

8. Asmundson, G. J.; Taylor, S. Role of anxiety sensitivity in pain-related fear and avoidance. J. Behav. Med. 19: 577-586; 1996.

9. Asmundson, G. J. G.; Wright, K. D.; Hadjistavropoulos, H. D. Anxiety sensitivity and disabling chronic health conditions: State of the art and future directions. Scand. J. Behav. Ther. 29:100-117; 2000. 
10. Aspinwall, L. G.; Richter, L.; Hoffman, III, R. R. Understanding how optimism works: An examination of optimists' adaptive moderation of belief and behavior. In: Chang, E. C., ed., Optimism \& pessimism: Implications for theory, research, and practice. Washington, DC: American Psychological Association; 2001:217-238.

11. Bandura, A. Self-efficacy: Toward a unifying theory of behavioral change. Psychol. Rev. 84:191-215; 1977.

12. Barlow, J. H.; Williams, B.; Wright, C. The Generalized Self-Efficacy Scale in people with arthritis. Arthritis Care Res. 9:189-196; 1996.

13. Boer, H.; Elving, W. J. L.; Seydel, E. R. Psychosocial factors and mental health in cancer patients: Opportunities for health promotion. Psychol. Health Med. 3:7179; 1998 .

14. Boersma, K.; Linton, S. J. Screening to identify patients at risk: Profiles of psychological risk factors for early intervention. Clin. J. Pain 21:38-43; 2005.

15. Bowley, D. M.; Butler, M.; Shaw, S.; Kingsnorth, A. N. Dispositional pessimism predicts delayed return to normal activities after inguinal hernia operation. Surgery 133:141-146; 2003.

16. Brenes, G. A.; Rapp, S. R.; Rejeski, W. J.; Miller, M. E. Do optimism and pessimism predict physical functioning? J. Behav. Med. 25:219-231; 2002.

17. Buer, N.; Linton, S. J. Fear-avoidance beliefs and catastrophizing: Occurrence and risk factor in back pain and ADL in the general population. Pain 99:485-491; 2002.

18. Carver, C. S.; Scheier, M. F. Optimism. In: Snyder, C. R.; Lopez, S. J., eds., Handbook of positive psychology. Oxford: University Press; 2005:231-243.

19. Chen, G.; Gully, S. M.; Eden, D. Validation of a new general self-efficacy scale. Organizational Res. Methods $4: 62-83 ; 2001$.

20. Dohnke, B.; Knauper, B.; Muller Fahrnow, W. Perceived self-efficacy gained from, and health effects of, a rehabilitation program after hip joint replacement. Arthritis Rheum. 53:585-592; 2005.

21. Dolce, J. J.; Doleys, D. M.; Raczynski, J. M.; Lossie, J.; Poole, L.; Smith, M. The role of self-efficacy expectancies in the prediction of pain tolerance. Pain 27:261272; 1986.

22. Fillingim, R. B.; Hastie, B. A.; Ness, T. J.; Glover, T. L.; Campbell, C. M.; Staud, R. Sex-related psychological predictors of baseline pain perception and analgesic responses to pentazocine. Biol. Psychol. 69:97$112 ; 2005$.

23. Fitzgerald, T. E.; Tennen, H.; Affleck, G.; Pransky, G. S. The relative importance of dispositional optimism and control appraisals in quality of life after coronary artery bypass surgery. J. Behav. Med. 16:25-43; 1993.

24. Fritz, J. M.; George, S. Z.; Delitto, A. The role of fearavoidance beliefs in acute low back pain: relationships with current and future disability and work status. Pain 94:7-15; 2001.

25. Gatchel, R. J.; Peng, Y. B.; Peters, M. L.; Fuchs, P. N.; Turk, D. The biopsychosocial approach to chronic pain: Scientific advances and future directions. Psychol. Bull. 133:581-624; 2007.

26. Goldberg, J.; Weisenberg, M.; Drobkin, S.; Blittner, M.;
Gotestam, K. G. Effects of manipulated cognitive and attributional set on pain tolerance. Cogn. Ther. Res. 21: 525-534; 1997.

27. Gramstad, A.; Iversen, E.; Engelsen, B. A. The impact of affectivity dispositions, self-efficacy and locus of control on psychosocial adjustment in patients with epilepsy. Epilepsy Res. 46:53-61; 2001.

28. Heuts, P. H.; Vlaeyen, J. W.; Roelofs, J.; de Bie, R. A.; Aretz, K.; van Weel, C.; van Schayck, O. C. Pain-related fear and daily functioning in patients with osteoarthritis. Pain 110:228-235; 2004.

29. Heye, M. L.; Foster, L.; Bartlett, M. K.; Adkins, S. A preoperative intervention for pain reduction, improved mobility, and self-efficacy. Appl. Nurs. Res. 15:174$183 ; 2002$.

30. Keefe, F. J.; Lefebvre, J. C.; Maixner, W.; Salley, Jr., A. N.; Caldwell, D. S. Self-efficacy for arthritis pain: relationship to perception of thermal laboratory pain stimuli. Arthritis Care Res. 10:177-184; 1997.

31. Keefe, F. J.; Rumble, M. E.; Scipio, C. D.; Giordano, L. A.; Perri, L. M. Psychological aspects of persistent pain: Current state of the science. J. Pain 5:195-211; 2004.

32. Keogh, E.; Asmundson, G. J. Negative affectivity, catastrophizing and anxiety sensitivity. In: Asmundson, G. J.; Vlaeyen, J. W. S.; Crombez, G., eds. Understanding and treating fear of pain. Oxford: University Press; 2004:91115 .

33. Keogh, E.; Birkby, J. The effect of anxiety sensitivity and gender on the experience of pain. Cognition Emotion 13:813-829; 1999.

34. Keogh, E.; Cochrane, M. Anxiety sensitivity, cognitive biases, and the experience of pain. J. Pain 3:320-329; 2002.

35. Keogh, E.; Dillon, C.; Georgiou, G.; Hunt, C. Selective attentional biases for physical threat in physical anxiety sensitivity. J. Anxiety Disord. 15:299-315; 2001.

36. Keogh, E.; Hamid, R.; Hamid, S.; Ellery, D. Investigating the effect of anxiety sensitivity, gender and negative interpretative bias on the perception of chest pain. Pain 111:209-217; 2004.

37. Keogh, E.; Mansoor, L. Investigating the effects of anxiety sensitivity and coping on the perception of cold pressor pain in healthy women. Eur. J. Pain 5:11-22; 2001.

38. Klenerman, L.; Slade, P. D.; Stanley, I. M.; Pennie, B.; Reilly, J. P.; Atchison, L. E.; Troup, J. D.; Rose, M. J. The prediction of chronicity in patients with an acute attack of low back pain in a general practice setting. Spine 20:478-484; 1995.

39. Lethem, J.; Slade, P. D.; Troup, J. D.; Bentley, G. Outline of a Fear-Avoidance Model of exaggerated pain perception-I. Behav. Res. Ther. 21:401-408; 1983.

40. Lilienfeld, S. O.; Turner, S. M.; Jacob, R. G. Further comments on the nature and measurement of anxiety sensitivity: A reply to Taylor. J. Anxiety Disord. 10: 411-424; 1996.

41. Linton, S. J. A review of psychological risk factors in back and neck pain. Spine 25:1148-1156; 2000.

42. Linton, S. J.; Buer, N.; Vlaeyen, J.; Hellsing, A. L. Are fear-avoidance beliefs related to the inception of an epi- 
sode of back pain? A prospective study. Psychol. Health 14:1051-1059; 2000.

43. Litt, M. D. Self-efficacy and perceived control: Cognitive mediators of pain tolerance. J. Pers. Soc. Psychol. 54:149-160; 1988.

44. Lowe, N. K. Self-efficacy for labor and childbirth fears in nulliparous pregnant women. J. Psychosom. Obstet. Gynaecol. 21:219-224; 2000.

45. Luszczynska, A.; Gutierrez Dona, B.; Schwarzer, R. General self-efficacy in various domains of human functioning: Evidence from five countries. Int. J. Psychol. 40:80-89; 2005.

46. Luszczynska, A.; Scholz, U.; Schwarzer, R. The general self-efficacy scale: Multicultural validation studies. J. Psychol. Interdisciplin. Applied 139:439-457; 2005.

47. McCracken, L. M.; Eccleston, C. A comparison of the relative utility of coping and acceptance-based measures in a sample of chronic pain sufferers. Eur. J. Pain 10: 23-29; 2006.

48. Nash, J. M.; Williams, D. M.; Nicholson, R.; Trask, P. C. The contribution of pain-related anxiety to disability from headache. J. Behav. Med. 29:61-67; 2006.

49. Novy, D. M.; Nelson, D. V.; Hetzel, R. D.; Squitieri, P.; Kennington, M. Coping with chronic pain: Sources of intrinsic and contextual variability. J. Behav. Med. 21: 19-34; 1998.

50. Orbell, S.; Johnston, M.; Rowley, D.; Davey, P.; Espley, A. Self-efficacy and goal importance in the prediction of physical disability in people following hospitalization: A prospective study. Br. J. Health Psychol. 6:25-40; 2001.

51. Peters, M. L.; Sommer, M.; de Rijke, J. M.; Kessels, A.; Heineman, E.; Patijn, J.; Marcus, M. A. E.; Vlaeyen, J. W. S.; van Kleef, M. Somatic and psychological predictors of long-term unfavourable outcome after surgical intervention. Ann. Surg. 245:487-494; 2007.

52. Philips, H. C. Avoidance behaviour and its role in sustaining chronic pain. Behav. Res. Ther. 25:273-279; 1987.

53. Picavet, H. S.; Vlaeyen, J. W.; Schouten, J. S. Pain catastrophizing and kinesiophobia: predictors of chronic low back pain. Am. J. Epidemiol. 156:1028-1034; 2002.

54. Radanov, B. P.; di Stefano, G.; Schnidrig, A.; Ballinari, $\mathrm{P}$. Role of psychosocial stress in recovery from common whiplash. Lancet 338:712-715; 1991.

55. Reiss, S.; Peterson, R. A.; Gursky, D. M.; McNally, R. J. Anxiety sensitivity, anxiety frequency and the predictions of fearfulness. Behav. Res. Ther. 24:1-8; 1986.

56. Rokke, P. D.; Fleming Ficek, S.; Siemens, N. M.; Hegstad, H. J. Self-efficacy and choice of coping strategies for tolerating acute pain. J. Behav. Med. 27:343-360; 2004.

57. Scheier, M. F.; Carver, C. S. Optimism, coping, and health: Assessment and implications of generalized outcome expectancies. Health Psychol. 4:219-247; 1985.

58. Scheier, M. F.; Carver, C. S. Effects of optimism on psychological and physical well-being: Theoretical overview and empirical update. Cogn. Ther. Res. 16:201228; 1992.

59. Scheier, M. F.; Carver, C. S.; Bridges, M. W. Distinguishing optimism from neuroticism (and trait anxiety, self-mastery, and self-esteem): A reevaluation of the Life Orientation Test. J. Pers. Soc. Psychol. 67:10631078; 1994.

60. Scheier, M. F.; Matthews, K. A.; Owens, J. F.; Magovern, Sr., G. J.; Lefebvre, R. C.; Abbott, R. A.; Carver, C. S. Dispositional optimism and recovery from coronary artery bypass surgery: The beneficial effects on physical and psychological well-being. J. Pers. Soc. Psychol. 57:1024-1040; 1989.

61. Schmidt, N. B.; Cook, J. H. Effects of anxiety sensitivity on anxiety and pain during a cold pressor challenge in patients with panic disorder. Behav. Res. Ther. 37:313323; 1999.

62. Severeijns, R.; Vlaeyen, J. W.; van den Hout, M. A.; Picavet, H. S. Pain catastrophizing and consequences of musculoskeletal pain: A prospective study in the Dutch community. J. Pain 6:125-132; 2005.

63. Sherer, M.; et al. The Self-efficacy Scale: Construction and validation. Psychol. Rep. 51:663-671; 1982.

64. Snyder, C. R.; Berg, C.; Woodward, J. T.; Gum, A.; Rand, K. L.; Wrobleski, K. K.; Brown, J.; Hackman, A. Hope against the cold: Individual differences in trait hope and acute pain tolerance on the cold pressor task. J. Pers. 73:287-312; 2005.

65. Snyder, C. R.; Rand, K. L.; Sigmond, D. R. Hope theory: A member of the positive psychology family. In: Snyder, C. R.; Lopez, S. J., eds. Handbook of positive psychology. Oxford: Oxford University Press; 2005: 257-276.

66. Snyder, C. R.; Sympson, S. C.; Michael, S. T.; Cheavens, J. Optimism and hope constructs: Warrants on a positive expectancy theme. In: Chang, E. C., ed. Optimism \& pessimism. Washington, DC: American Psychological Association; 2001:101-126.

67. Sommer, M.; de Rijke, J. M.; Marcus, M. A. E.; Kessels, A.; Peters, M. L.; Geurts, J.; Patijn, J.; Gramke, H.-F.; van Kleef, M. Predictors of postoperative pain in an university hospital population. Submitted.

68. Stegen, K.; Van Diest, I.; Van de Woestijne, K. P.; Van den Bergh, O. Negative affectivity and bodily sensations induced by $5.5 \% \mathrm{CO}_{2}$ enriched air inhalation: Is there a bias to interpret bodily sensations negatively in persons with negative affect? Psychol. Health 15:513-525; 2000.

69. Stegen, K.; Van Diest, I.; Van de Woestijne, K. P.; Van den Bergh, O. Do persons with negative affect have an attentional bias to bodily sensations? Cognition Emotion 15:813-829; 2001.

70. Stein, M. B.; Jang, K. L.; Livesley, W. J. Heritability of anxiety sensitivity: A twin study. Am. J. Psychiatry 156: 246-251; 1999.

71. Sullivan, M. J. L.; Thorn, B.; Haythornthwaite, J. A.; Keefe, F.; Martin, M.; Bradley, L. A.; Lefebvre, J. C. Theoretical perspectives on the relation between catastrophizing and pain. Clin. J. Pain 17:52-64; 2001.

72. Taylor, S. The structure of fundamental fears. J. Behav. Ther. Exp. Psychiatry 24:289-299; 1993.

73. Taylor, S. Anxiety sensitivity: Theoretical perspectives and recent findings. Behav. Res. Ther. 33:243-258; 1995.

74. Tennen, H.; Affleck, G.; Urrows, S.; Higgins, P.; et al. 
Perceiving control, construing benefits, and daily processes in rheumatoid arthritis. Can. J. Behav. Sci. 24: $186-203 ; 1992$.

75. Treharne, G. J.; Kitas, G. D.; Lyons, A. C.; Booth, D. A. Well-being in rheumatoid arthritis: The effects of disease duration and psychosocial factors. J. Health Psychol. 10:457-474; 2005.

76. Vancleef, L. M. G.; Peters, M. L. Examining content specificity of negative interpretation biases with the Body Sensations Interpretation Questionnaire (BSIQ). Submitted.

77. Vancleef, L. M. G.; Peters, M. L.; Gilissen, S. M. P.; de Jong, P. J. Understanding the role of injury/illness sensitivity and anxiety sensitivity in pain processing: An examination using the Extrinsic Affective Simon Task. J. Pain 8:563-572; 2007.

78. Vancleef, L. M. G.; Peters, M. L.; Roelofs, J.; Asmundson, G. J. G. Do fundamental fears differentially contribute to pain-related fear and pain catstrophizing? An evaluation of the sensitivity index. Eur. J. Pain 10:527-536; 2006.

79. Vancleef, L. M. G.; Peters, M. L.; van Aken, N. Manipulated control and self-efficacy influence fear and painfulness of an experimentally induced pain. In preparation.

80. Vlaeyen, J. W.; Linton, S. J. Fear-avoidance and its con- sequences in chronic musculoskeletal pain: A state of the art. Pain 85:317-332; 2000.

81. Wahl, A. K.; Rustoen, T.; Hanestad, B. R.; Gjengedal, E.; Moum, T. Self-efficacy, pulmonary function, perceived health and global quality of life of cystic fibrosis patients. Soc. Indicators Res. 72:239-261; 2005.

82. Waldrop, D.; Lightsey, Jr., O. R.; Ethington, C. A.; Woemmel, C. A.; Coke, A. L. Self-efficacy, optimism, health competence, and recovery from orthopedic surgery. J. Counseling Psychol. 48:233-238; 2001.

83. Watson, D.; Clark, L. A.; Harkness, A. R. Structures of personality and their relevance to psychopathology. J. Abnorm. Psychol. 103:18-31; 1994.

84. Watson, D.; Pennebaker, J. W. Health complaints, stress, and distress: Exploring the central role of negative affectivity. Psychol. Rev. 96:234-254; 1989.

85. Woby, S. R.; Watson, P. J.; Roach, N. K.; Urmston, M. Coping strategy use: does it predict adjustment to chronic back pain after controlling for catastrophic thinking and self-efficacy for pain control? J. Rehabil. Med. 37:100-107; 2005.

86. Zelman, D. C.; Howland, E. W.; Nichols, S. N.; Cleeland, C. S. The effects of induced mood on laboratory pain. Pain 46:105-111; 1991. 